\title{
The simulation and design air conditioner in unit 103 of south pars with use advance exergy
}

\author{
Mohsen Darabi ${ }^{1 *}$, Mohammad Mohammadiun ${ }^{2}$, Hamid Mohammadiun ${ }^{2}$, Saeed Mortazavi ${ }^{3}$, Heydar Maddah ${ }^{4}$ \\ ${ }^{I}$ Department of Chemical Engineering, Azad University of Shahrood Branch, Shahrood, Iran \\ ${ }^{2}$ Assistant Professor, Department of Mechanical Engineering, Shahrood Branch, Islamic Azad University, Shahrood, Iran \\ ${ }^{3}$ Assistant Professor, Department of chemical Engineering, Shahrood Branch, Islamic Azad University, Shahrood, Iran \\ ${ }^{4}$ Department of Chemical Engineering, Azad University of Shahrood Branch, Shahrood, Iran \\ *Corresponding author E-mail: mohsendarabi313@yahoo.com
}

Copyright $\odot 2015$ Mohsen Darabi et al. This is an open access article distributed under the Creative Commons Attribution License, which permits unrestricted use, distribution, and reproduction in any medium, provided the original work is properly cited.

\begin{abstract}
In this paper, energy recycling for distillation tower condenser was done by use of heat integration method. At first, we calculated the amount of condensation energy (QAir Cooler), in air cooler, and then we calculated energy consumption in this equipment based on annual balance (5460 GJ per year). Then, based on heat integration (energy unification), two conditions were proposed to use the current energies in the process for supplying condensation energy (QAir Cooler): first, its must be lesser than condensing temperature of condenser $\left(55^{\circ} \mathrm{C}\right)$ (the major condition). Second, it must have much more flow rate than the overhead flow. According to two above conditions, the food flow as chosen as the integration factor and its amount of energy (EStream) is calculated from the Enthalpy equation as $9863964 \mathrm{kj} / \mathrm{h}$. As EFeed >> QAir Cooler and food flow temperature to condense an overhead vapor is satisfying. The food flow can be used to condense the saturated vapor to $55^{\circ} \mathrm{C}$. in case of using food energy and using heat exchanger instead of air cooler; $5460 \mathrm{GJ}$ energy will be saved annually. By using heat exchanger and omitting air cooler, the unit103 operating costs will be reduced considerably. Economically, conducting such a project will demand investing costs. However, obtainable incomes from doing this project (electricity consumption recycling and cost's reduction) reveal this fact that capital return rate and the project benefits for unit 103 of South Pars phases $2 \& 3$ are beneficial.
\end{abstract}

Keywords: Design and Simulation; Energy Recovery; Heat Integration; Air Conditioner.

\section{Introduction}

Thermal integration expresses the way of heat recovering, and. In concise, process integration means: General and systematic models for integrated designing of production systems, inseparable processes all over of the site with an emphasis on the effective use of energy and reducing environmental impacts. This is the obvious point of the designing methods, but the word of integration means a process for describing physical arrangement such as connecting equipments and process lines in the Unit [1-3]. The following cases are the reasons for the use of process's integration in Units and designing [3-5]: reducing annual costs by means of determining the parallel relationship between operation costs (raw materials and energy) and investment cost (equipment). The parallel relationship condition in the processes' integration can be in reducing energy consumption, improving he raw materials consumption and reducing equipment's cost.

Increasing production capacity (Unit capacity) by using process integration for removing bottlenecks

1) Reducing process problems (startup and shutdown) with the most correction which is the most use of process integration.

2) Increasing the process controllability (is from inner tool and is different from process controlling). Simplify the control by choosing the Unit (topology) inter connectors and equipments parameters without considering the system real control. 
To ensure system flexibility by considering unit characteristics (raw materials and or new products, the production capacity compatibility and etc.) and unwelcome (such as exchanger fouling and catalysts inactivity) when opposing with operating conditions change, by proper choose of Unit interconnectors and equipments features.

3) Unwilling reduction of the Unit wastes, for example, reduction of fossilized fuels, connection to auxiliary resources of energy generation, closed processes and etc.

4) Adding some challenges to industrial processes and community in order to have a stable development.

The stating point of process integration for energy consumption reduction is 1980 . From 1980 onwards, some methods were developed for industrial applications such as the total of annual costs, application in Unit and the Unit flexibility. Nowadays, social estimations such as environment, nutrition are an inseparable part in the process integration. The main reason for achieving benefits of using process integration is, in fact, matters, which make us closed to systems requirements. Most of the units in the industry have very complicated inner inter connectors such as advanced components; as the result of being so, we will be closed to the Unit basic requirements. The local researches are absolutely effective in optimization. In the thermal integration level, the process integration can determine the optimal level of thermal wastes, which are compatible with designing of exchangers networks in terms of the least costs of equipments. In the level of heat and Tolen, the process integration can determine the optimal amount of loading and or the consumption level and or vapor production and also the positions of heat and power systems combination. In proper economic and thermodynamic optimization, the proper process of heat pup can be chosen by using graphical diagrams and systematic methods. In terms of the Unit production increase, the process integration can be used in removing the bottlenecks to increase production capacity [6-9]. As an obvious example, consider an energy system which has mass flow limitation during the process. This event is always seen when the furnace is working at its maximum capacity in the most of the oil refining units. The integration is also effective in avoidance of investing in the sections of supportive units by using optimum recycling of heat in the process. When the operation is under consideration, controllability and flexibility of the Unit revealed that most time the major wastes were in the inner interconnectors. The process integration has a more focus on the process structure. The methods' compatibility is a vital tool for finding the wastes related to the unit operation. As an example, the Unit flexibility may be achieved from installing additional equipments and components more than the Unit real requirements. In such a condition, the process integration can be used in determining the additional investment place for determining the effective flexible capital. In the environment and stable development, the process integration presents the systematic methods to reduce capital, to comply the government regulations and community expectations. Reducing polluting gasses and wastewater is an example of its benefits (means reducing water consumption).Finally,one can say that the processes' integration results cause an increase in information relating to key elements and the dependents in the Units (11-9).

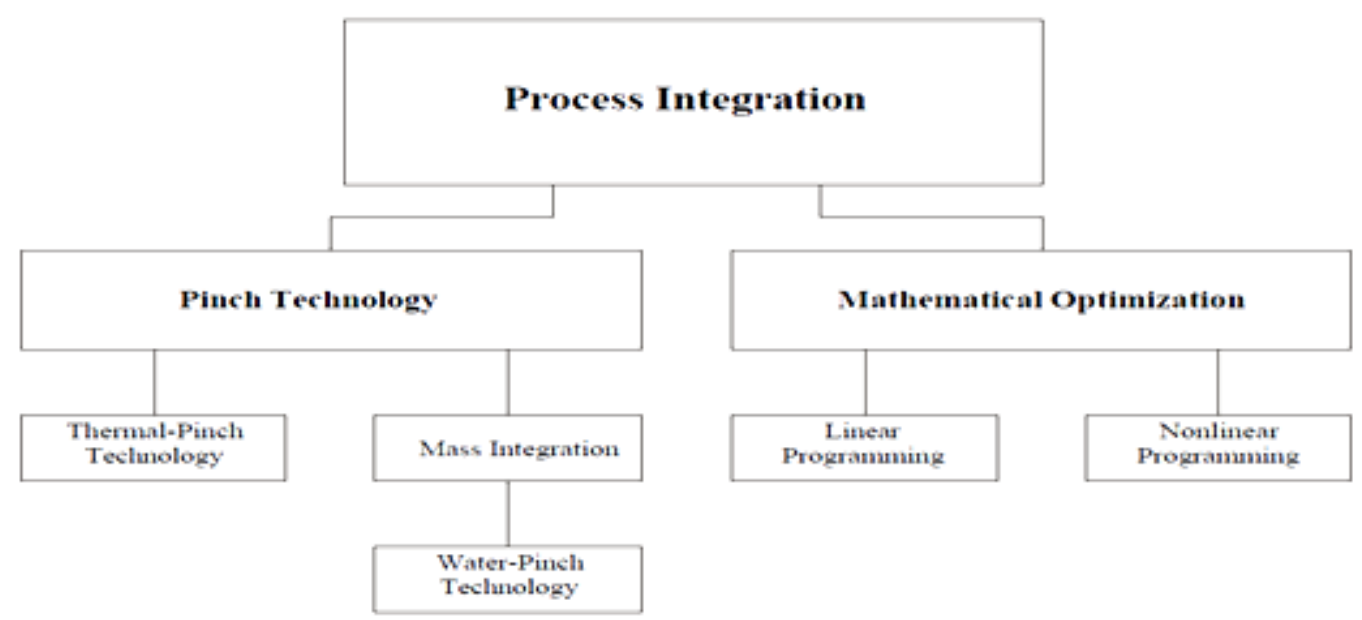

Fig. 1: The Relationship between the Process Integration Branches

The thermal integration is a method to minimize energy consumption based on thermodynamic equations. This objective can be achieved by optimizing heat recovery systems, methods of supplying the process energy and its operation conditions. This technology is known as thermal integration, energy integration or pinch technology integration [11].

Pinch technology is a heat exchanger network design ensures minimal energy consumption. Exergy analysis uses the first and second laws of thermodynamics to compute exergy flows in the system and to determine non-optimized components. On the other hand, pinch technology is a general method to designing the processes that it can target the largest possible correction before final designing and simulating. However, the disadvantage of this approach becomes apparent when it is used in power generation systems. Therefore, a new method to overcome the weaknesses of these two methods was developed called pinch and Exergy combined analysis. This new method can be used to optimize the systems such as power plants. Some refineries are running a special technique called hydrogen pinch to minimize the amount of investment costs by implementation of an efficient management of resources on hydrogen and its supplying resources and to gain economic profit in a short term by a thrift in these reduced costs. In this approach, the first law of 
thermodynamics was used to calculate the enthalpy changes in passing flow from a heat exchanger, and the second law was used to determine the heat direction. In traditional designing, the process is design at first and then the mass, temperature and flow rate are defined through balancing. Then, the thermal system designing is completed and the remaining cases are determined. Each of these steps can be performed independently. However, in a pinch designing, the process integration offers solutions to minimize energy consumption by using pinch technology before designing the network heat recovery. The limitations of the heat and utility recovery systems were considered later on. Pinch designing determines process optimizing chances and heat integration improvement. This method helps optimization of heat transfer equipments during theirs designing [11].

\section{The need for energy efficiency in industry}

Applying special methods to determine the effective and economic way in a process is called optimization. Optimization is one of the most important decision-making tools in the industry. Optimization chooses the best response or solution from possible responses by applying effective and quantity approaches. However, computer and related software make the required calculations possible with the least costs. Saving energy is always one the most significant considering issues in designing a chemical unit. Moreover, determining the least amount of heat and cold energy needed by a process is one of the major calculations for determining the amount of energy savings. Therefore, thermal integration (energy unification) is one of the major factors in economic designs. The brand of pinch technology is known for active researchers and scholars in the field optimization. This technology is used in analyzing and investigating the heat exchanger network in order to reduce energy consumption [12].

Vredeveld and Linnhoff investigated the thermodynamic approach to reduce energy consumption in heat exchanger in the end of the 1970s century. And they introduced concepts like combined curve as an important tool in the heat energy recycling [13]. Pinch technology has developed over times, as it is used in the heat exchanger network to optimize energy consumption in the distillation towers, furnaces, evaporators, turbines, reactors. However, this technology faced some problems such as limitation of pressure drop in modifying the current systems, Unit complexity, piping cost, safety problems and etc. The problem of pressure drop was obviated in the beginning of 1990s and in the middle of 1990s, the regional matters that made this technology impossible to operate and uneconomic were resolved [13]. Pinch analyzing tools of integrated curve and the integrated curve are comprehensive (figure 2).
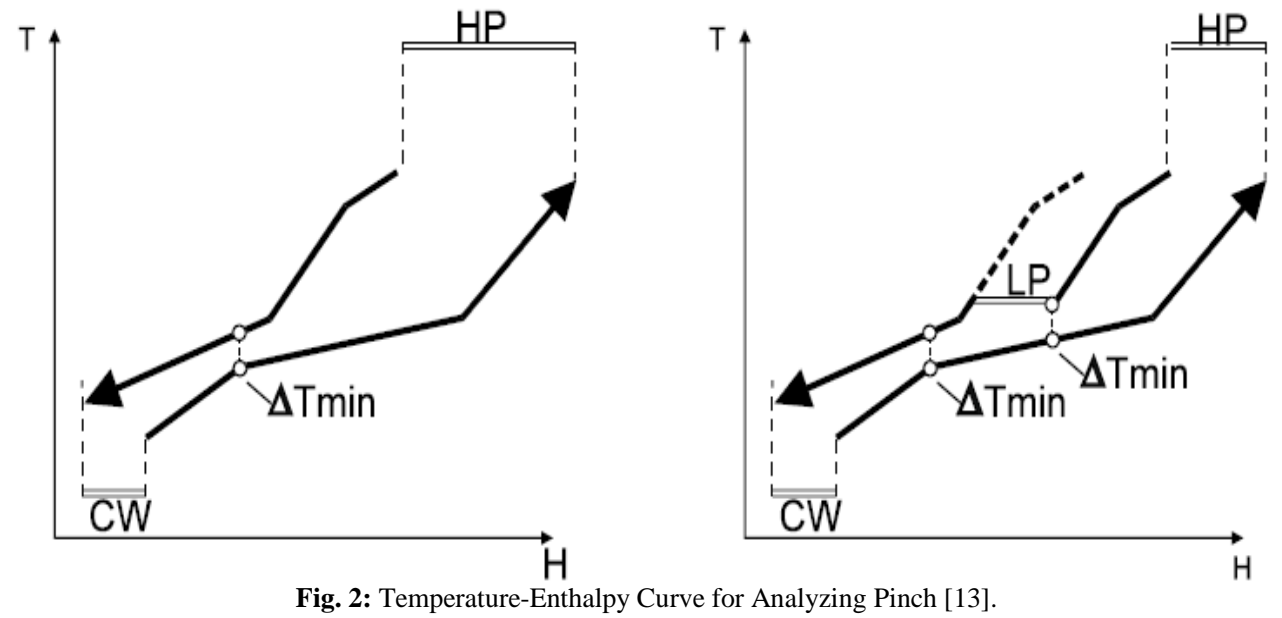

\section{Calculating energy consumption in condenser of stabilization tower}

In the stabilization tower, the aim is to separate the light gasses and hydrocarbons from input food. As a result, the upper part of the distillation tower almost includes light compounds and a few heavy compounds.

The stabilizing tower overhead vapor will be sent to an air conditioner (condenser) at the pressure of 1020kpa and the temperature of $67^{\circ} \mathrm{C}$ in a saturated form. In this air conditioner with a pressure drop beyond 50kpa, the input saturated vapor condenses to $55^{\circ} \mathrm{C}$ (figure 3 ). 


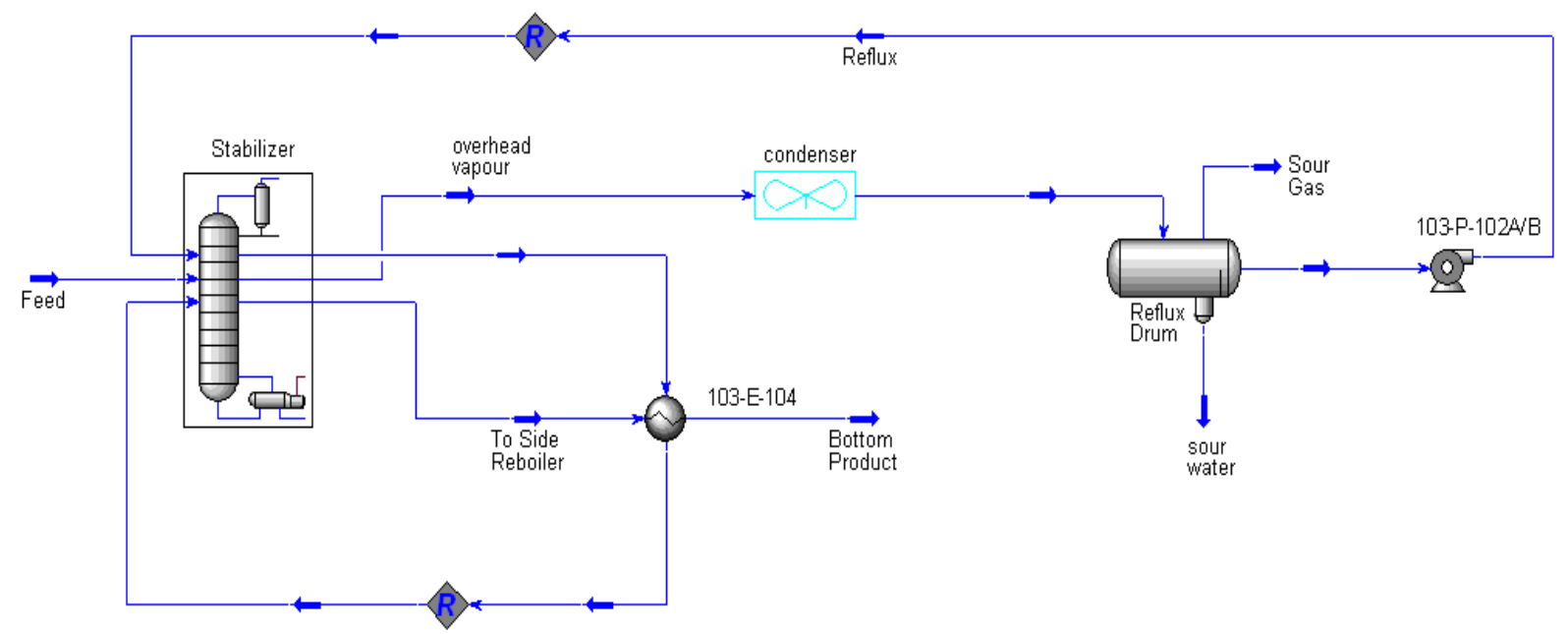

Fig. 3: Stabilization Modeling

The output flow from the condenser is sent to the separator in a two-phase form (98\% vapor and 2 percent liquid) where liquid phases and vapor are separated. The overhead vapor of this separator (this flow includes the amount of hydrogen sulfide) comprises of light gases, which are sent with other gases to gas refinery section. The obtained liquid from the vertical separator is returned to a distillation tower again [14]. The amount of energyconsumption in the air conditioner (condenser) with consideration of the input and output differences $\mathrm{T} \Delta$ )) and overhead vapor flow rate is very much $(17840 \mathrm{~kg} / \mathrm{h})$ that it's supplying cost is considerable. The amount of required energy for overhead vapor condensation is calculated to $55^{\circ} \mathrm{C}$ by use of energy balancing over air cooler:

- $\quad$ Q Air Cooler $=\mathrm{m}[(\mathrm{Cp} \times \mathrm{T})$ Out $-(\mathrm{Cp} \times \mathrm{T}) \mathrm{In}]$

Where the amount of consumed energy in the air cooler is based on $\mathrm{Cp}, \mathrm{k} \mathrm{j} / \mathrm{h}$; heat capacity is based on $\mathrm{kj} / \mathrm{kg}-\mathrm{C}$; temperature $(\mathrm{T})$ is based on centigrade; and $\mathrm{m}$ represents the input mass flow rate to air cooler based $\mathrm{kg} / \mathrm{h}$.

- $\quad$ QAir Cooler $=17840[(1.946 \times 55)$ Out $-(1.974 \times 67) \mathrm{In}]$

QAir Cooler $=450067.52 \mathrm{kj} / \mathrm{h}=125 \mathrm{kj} / \mathrm{sec}=125 \mathrm{KW}$

For one working year, we have.

QAir Cooler $=125 \mathrm{kj} / \mathrm{sec} \times 3600 \mathrm{sec} / 1 \mathrm{~h} \times 24 \mathrm{~h} / 1$ day $\times 365$ day $/ 1$ year

QAir Cooler $=3942000000 \mathrm{kj} /$ year $=3942 \mathrm{Gj} /$ year

\section{4. condenser heat integration}

To calculate the condenser integration, we will do as the following:

1) At first, we will calculate the required energy to condensate (QAir Cooler) overhead vapor

2) Then, based on energy analysis, we will determine the required flow to supply cooling need

3) We will compare the energy of the determined flow from the step 2 (EStream) and or the required energy to condensate overhead vapor.

The calculation of the required energy to condensate the overhead vapor:

- QAir Cooler $=\mathrm{m}[(\mathrm{Cp} \times \mathrm{T})$ Out $-(\mathrm{Cp} \times \mathrm{T}) \mathrm{In}]$

- $\quad$ QAir Cooler $=17840[(1.946 \times 55)$ Out $-(1.974 \times 67) \mathrm{In}]$

QAir Cooler $=450067.52 \mathrm{kj} / \mathrm{h}=125 \mathrm{kj} / \mathrm{sec}=125 \mathrm{KW}$

Based on energy analysis to overhead vapor by one of the processing flows, that flow must have two conditions: first, its must be lesser than condensing temperature of condenser $\left(55^{\circ} \mathrm{C}\right)$ (the major condition). Second, it must have much more flow rate than the overhead flow. Based on the obtained thermal information for the processing flows from economic software HYSYS and the aforementioned conditions, the food flow obeys two aforementioned conditions. This flow temperature is $22^{\circ} \mathrm{C}$ and it mass flow rate is $205200 \mathrm{~kg} / \mathrm{h}$. The food flow energy will be calculated based on Enthalpy relation as follows:

EFeed $=\mathrm{CP} \times \mathrm{T}$

$\mathrm{CP}=\mathrm{m}(\mathrm{kg} / \mathrm{h}) \times \mathrm{Cp}(\mathrm{kj} / \mathrm{kg}-\mathrm{C})$

EFeed $=205200 \times 2.185 \times 22=9863964 \mathrm{kj} / \mathrm{h}=2739.99 \mathrm{KW}$

According to above calculations, the food flow energy is nearly 22 times of the required energy to condense the overhead vapor in air cooler (EFeed $=22$ QAir Cooler). Thus, it can be used to condense the overhead vapor. To use food flow to operation of vapor condensing, the required surface for transferring heat should be prepared between these to flows. To this end, the use of heat exchanger instead of an air cooler is proposed.

Because the food flow energy is much more than the required energy for condensation, the heat surface will not very large and the number of exchanger pipes will not be large. Consequently, the used heat exchanger is of fewer costs. To design heat exchanger, the software Aspen Bjac is used; and to design heat exchanger in the environment of software 
Bjac, the output food flow temperature, after heat exchanging with overhead vapor, is necessary as one of the input information into software, which can be calculated from energy balancing over the heat exchanger (figure 4).

$\Delta \mathrm{H}=0=[\mathrm{CP}($ Tout - Tin $)]$ Vapour $+[\mathrm{CP}($ Tout - Tin $)]$ Feed

$\mathrm{CP}=\mathrm{m}(\mathrm{kg} / \mathrm{h}) \times \mathrm{Cp}(\mathrm{kj} / \mathrm{kg}-\mathrm{C})$

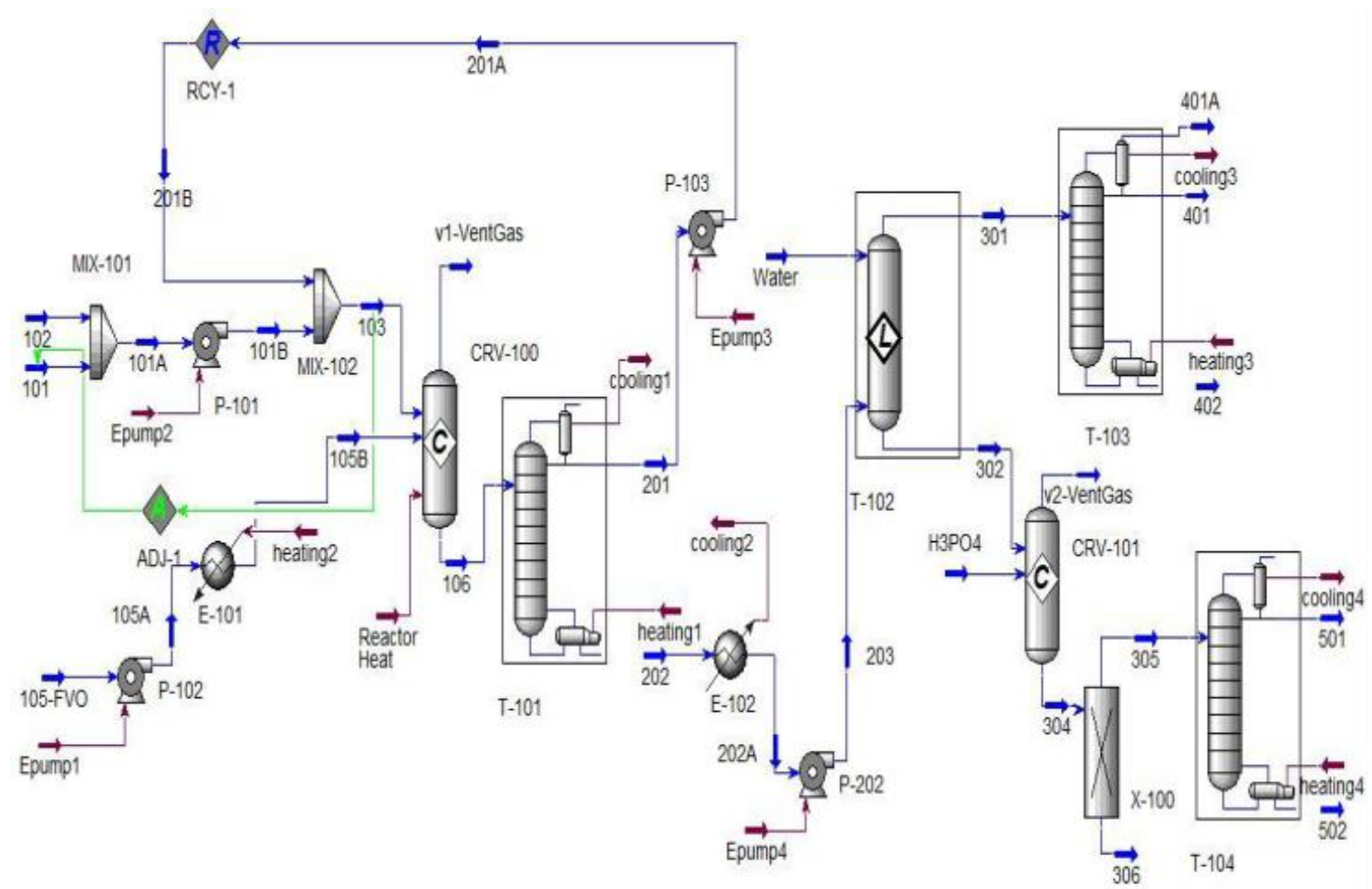

Fig. 4: Advanced Simulation

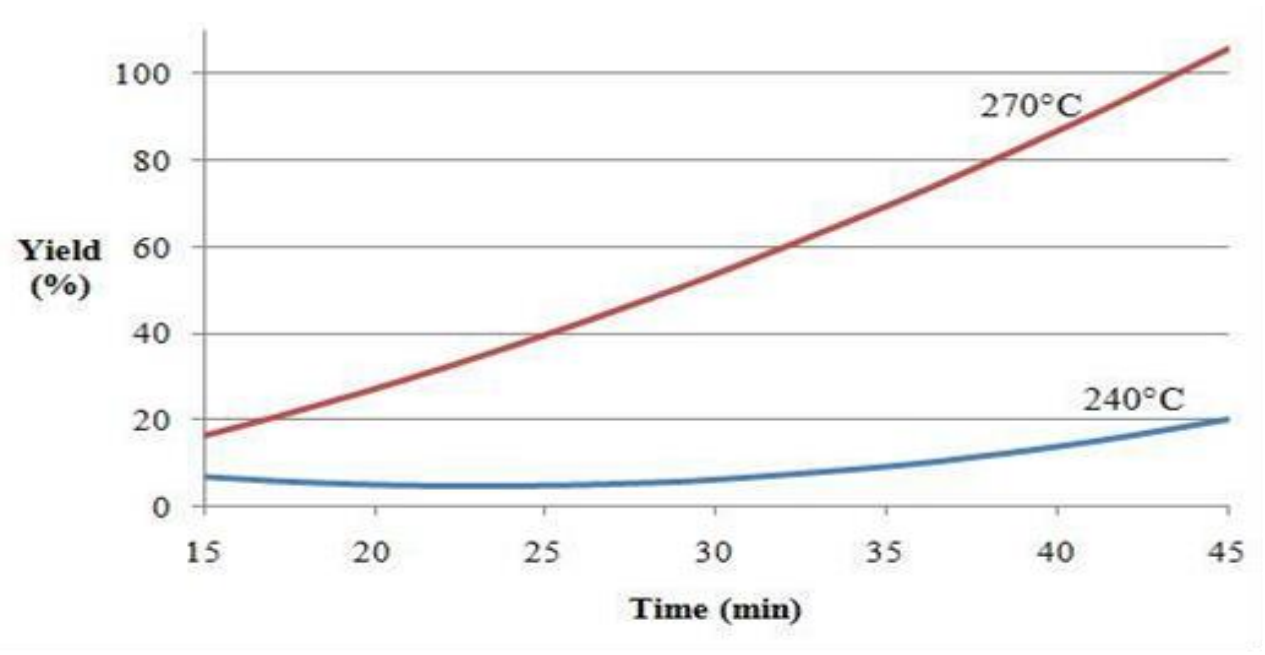

Fig. 5: The Way of Heat Exchanging Between Hot and Cold Flows in the Thermal Field

By solving the above one- unknown equation, the temperature of food flow is 22.73 after exchanging heat with overhead vapor of a distillation tower. Having the required energy for condensation (QAir Cooler) and the food flow temperature one can design heat exchanger after exchanging heat and entering these information into software. 


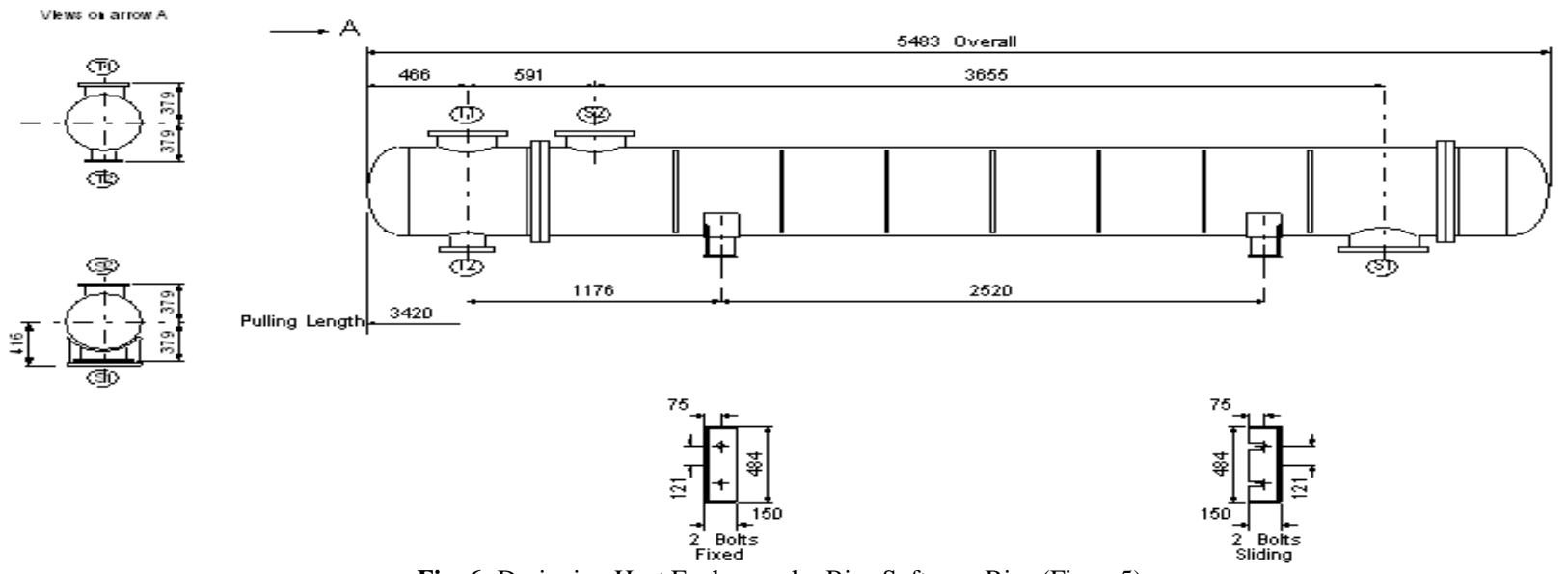

Fig. 6: Designing Heat Exchanger by Bjac Software Bjac (Figure5)

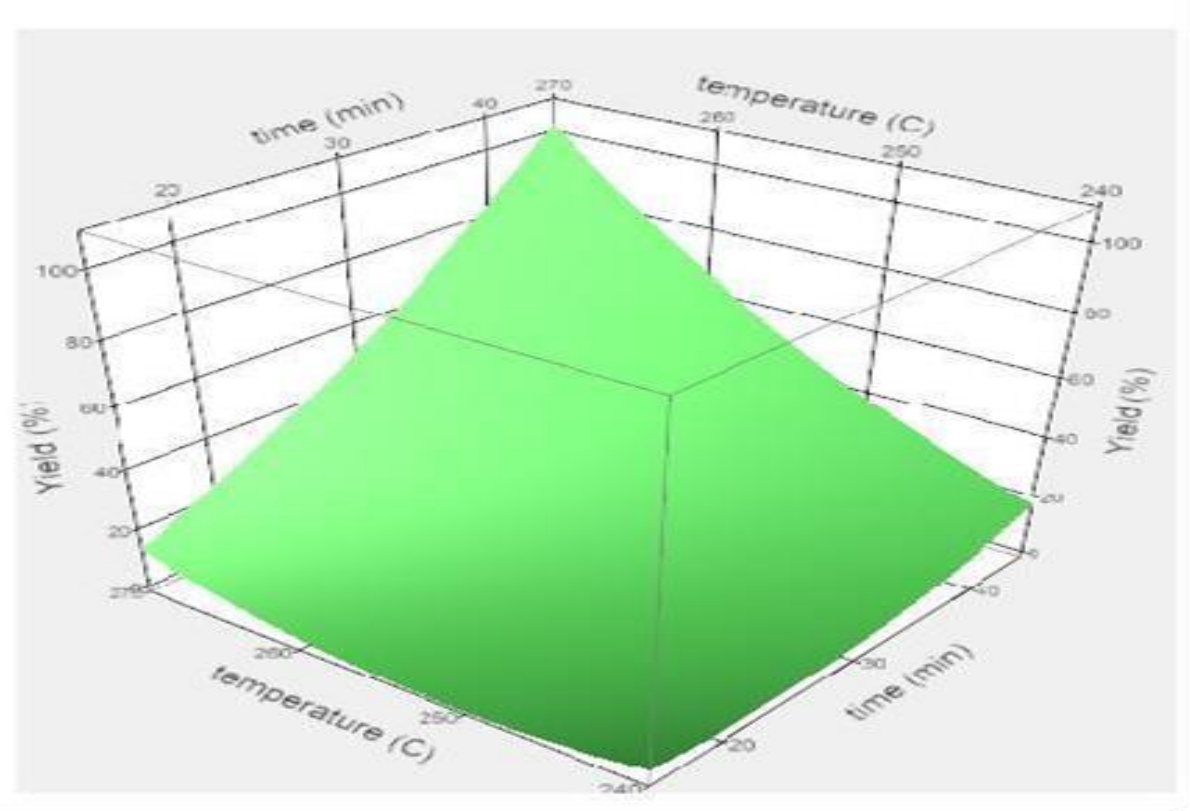

Fig. 7: Temperature \&Time for Design Heat Exchanger

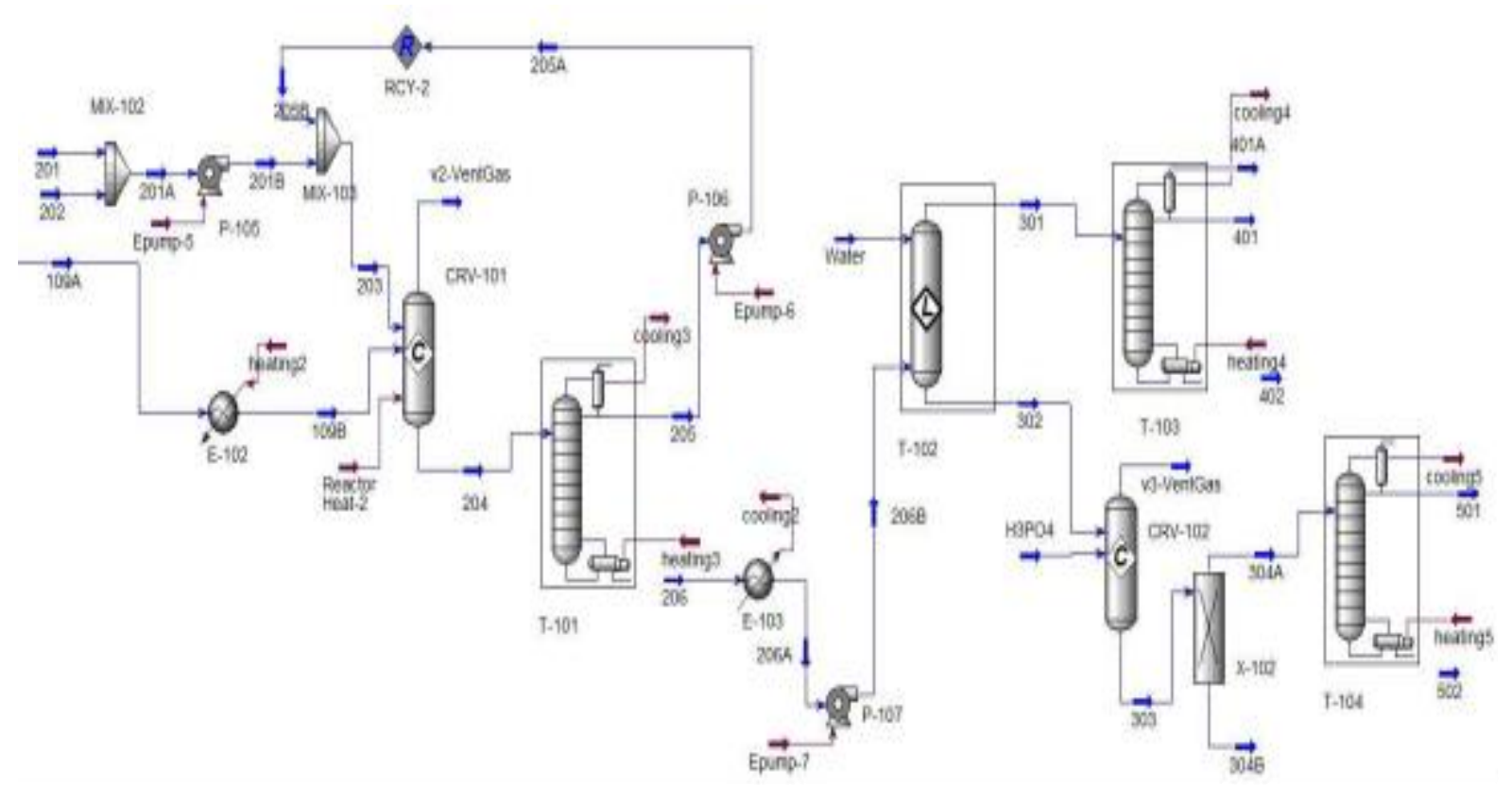

Fig. 8: Advanced Simulation Final 


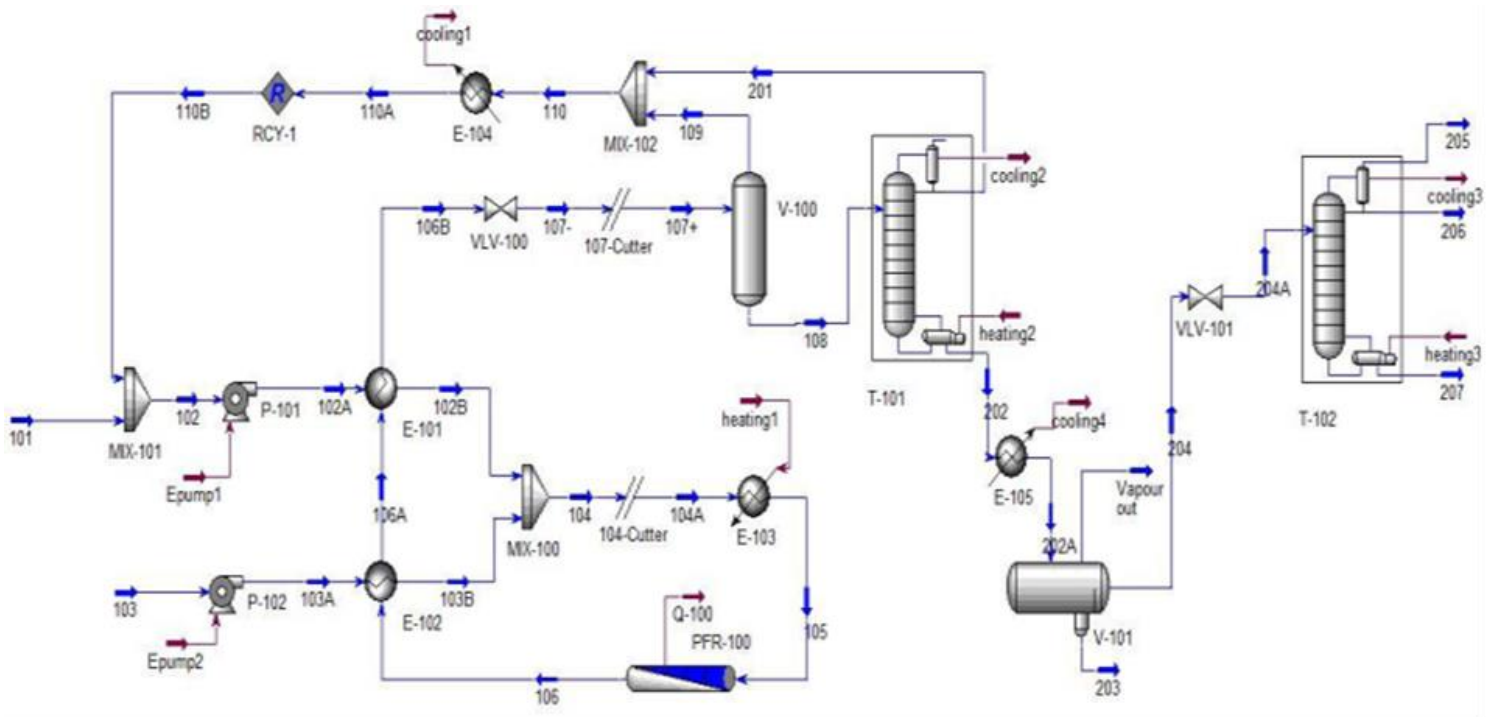

Fig. 9: Heat Exchanging Between Hot and Cold Flows in the Thermal Field.

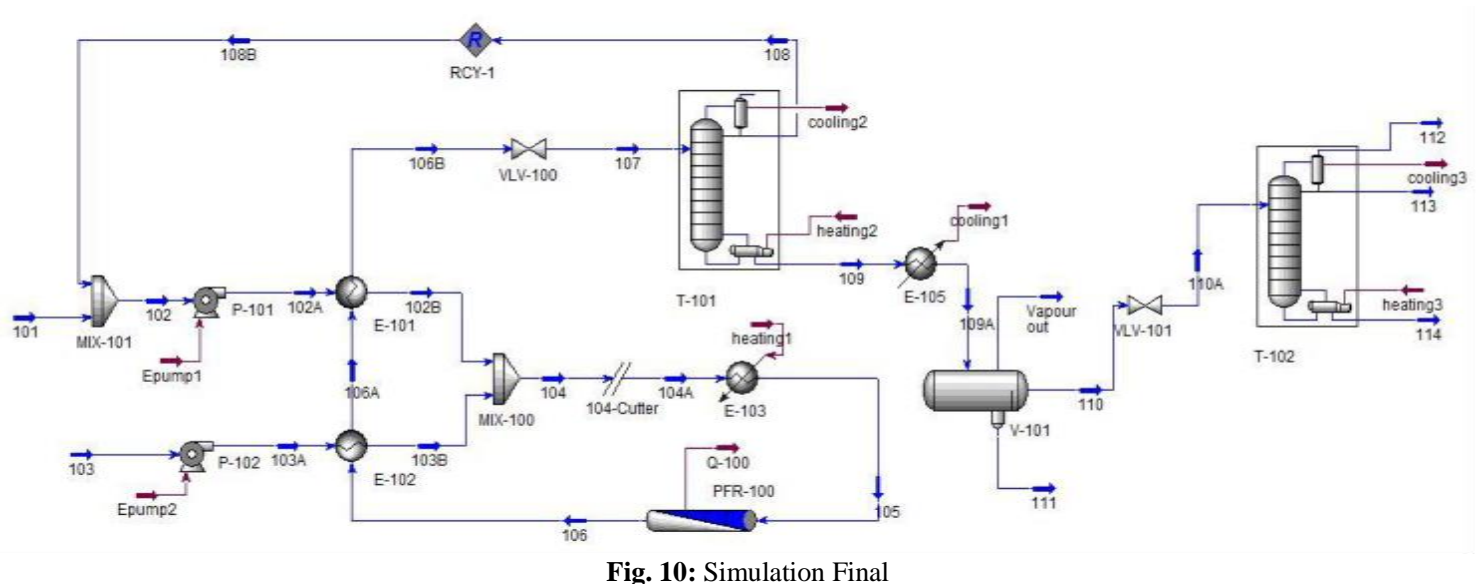

Fig. 10: Simulation Final

\section{Conclusion}

In this paper, energy recycling for distillation tower condenser was done by use of heat integration method. At first, we calculated the amount of condensation energy (QAir Cooler), in air cooler, and then we calculated energy consumption in this equipment based on annual balance (3942 GJ per year). Then, based on heat integration (energy unification), two conditions were proposed to use the current energies in the process for supplying condensation energy (QAir Cooler): first, its must be lesser than condensing temperature of condenser $\left(55^{\circ} \mathrm{C}\right)$ (the major condition). Second, it must have much more flow rate than the overhead flow. According to two above conditions, the food flow as chosen as the integration factor and its amount of energy (EStream) is calculated from the Enthalpy equation as9863964 kj/h. As EFeed $\gg$ > QAir Cooler and food flow temperature to condense an overhead vapor is satisfying. The food flow can be used to condense the saturated vapor to $55^{\circ} \mathrm{C}$. in case of using food energy and using heat exchanger instead of air cooler. 3942 GJ energy will be saved annually. By using heat exchanger and omitting air cooler, the unit103 operating costs will be reduced considerably. Economically, conducting such a project will demand investing costs. However, obtainable incomes from doing this project (electricity consumption recycling and costs reduction) reveal this fact that capital return rate and the project benefits for unit103 of South Pars phases $2 \& 3$ are beneficial.

\section{References}

[1] M.S.L. Lababidi, I.M. Alatiqi, L.J. Nayfeh, "Energy retrofits study of an ammonia plant", Applied Thermal Engineering, Vol. 20, (2000) 1495-503. http://dx.doi.org/10.1016/S1359-4311(00)00020-X.

[2] Pinch Technology: Basics for the Beginners, www.cheresources.com

[3] M.M. El-Halwagi, V. Manousiouthakis, "Synthesis of Mass Exchanger Network", AIChE J., Vol. 8, (1989) 1233-1244. http://dx.doi.org/10.1002/aic.690350802.

[4] M.S.L. Lababidi, I.M. Alatiqi, L.J. Nayfeh, "Energy retrofits study of an ammonia plant", Applied Thermal Engineering, Vol. 20, (2013)1495503. http://dx.doi.org/10.1016/S1359-4311(00)00020-X.

[5] Pinch Technology: Basics for the Beginners, www.cheresources.com 
[6] M.M. El-Halwagi, Polley, "Synthesis of Mass Exchanger Network", AIChE J., Vol. 8, (2011) 1233-1244.

[7] D.R. Morris," Exergy analysis and cumulative exergy consumption of complex chemical process", Chemical Engineering Science, Vol.40, No.2, (2009) 459-456.

[8] J. Szargut, D.R. Morris, F.R .Steward, Exergy Analysis of Thermal, Chemical and Metallurgical process, Hemisphere publishing, New York, (2011).

[9] A.C. Neto, P. Pilidis, "An Exergy Analysis of Novel Power Generation Systems", ASME, (2008) 290-294

[10] Towler .P. "Integrated process design for improved energy efficiency." Linnh off B, DR and Wardle I (1979) Understanding Heat Exchanger Networks, Comp Chem Eng, 3:295

[11] Mathur.R.M. "Process Integration through Pinch Analysis", User Guide on Process Integration for the Efficient Use of Thermal Energy by Linnhoff \& others, Published by "The Institution of Chemical Engineers, Geo. E. Davis Building, 165 - 171 Railway Terrace, Rugby, Warks, CV21 3HQ, England", 1982.

[12] Shenoy, U.V., Sinha, A. and Bandy opadhyay, S. (1998) "Multiple utilities targeting for heat exchanger networks", Trans. IChemE. Chem. Eng. Res. Des., 76, Part A, March, 259-272 http://dx.doi.org/10.1205/026387698524910.

[13] Lee, "Application of exergy and Pinch analysis on oleochemical fractionation process.” Linnhoff B, D.W. Townsend, D. Boland, G.F. Hewitt, B.E.A. Thomas, A.R.Guy, and R.H. Marsland, 1982, User Guide on Process Integration for the Efficient Use of Energy, IChemE, Rugby, U.K.

[14] Documents of south pars field development-phases $2 \& 3$, condensate stabilization unit 103. 